\title{
Canadian Association of Gastroenterology position statement on screening individuals at average risk for developing colorectal cancer: 2010
}

\author{
Desmond J Leddin MB FRCPC ${ }^{1}$, Robert Enns MD FRCPC ${ }^{2}$, Robert Hilsden MD FRCPC ${ }^{3}$, Victor Plourde MD PhD ${ }^{4}$, \\ Linda Rabeneck MD MPH FRCPC ${ }^{5}$, Daniel C Sadowski MD FRCPC ${ }^{6}$, Harminder Singh MD FRCPC ${ }^{7}$
}

\begin{abstract}
DJ Leddin, R Enns, R Hilsden, et al. Canadian Association of Gastroenterology position statement on screening individuals at average risk for developing colorectal cancer: 2010. Can J Gastroenterol 2010;24(12):705-714.

The Canadian Association of Gastroenterology and the Canadian Digestive Health Foundation published guidelines on colon cancer screening in 2004. Subsequent to the publication of these guidelines, many advances have occurred, thereby necessitating a review of the existing guidelines in the context of new technologies and clinical knowledge. The assembled guideline panel recognized three recent American sets of guidelines and identified seven issues that required comment from a Canadian perspective. These issues included, among others, the role of program-based screening, flexible sigmoidoscopy, computed tomography colonography, barium enema and quality improvement. The panel also provided context for the selection of the fecal immunochemical test as the fecal occult blood test of choice, and the relative role of colonoscopy as a primary screening tool. Recommendations were also provided for an upper age limit for colon cancer screening, whether upper endoscopy should be performed following a negative colonoscopy for a positive fecal occult blood test and when colon cancer screening should resume following negative colonoscopy.
\end{abstract}

Key Words: Colorectal neoplasia; Disease prevention; Screening

Oolon cancer is a leading cause of cancer-related morbidity and mortality in Canada. In 2009, it was estimated that approximately 22,000 Canadians would be diagnosed with colon cancer and 9100 would die from the disease (1).

The burden of this malignancy can be reduced by preventing the development of cancer and by detecting established tumours at an earlier stage of development. The earlier the stage at which the cancer is detected, the better the prognosis.

The Canadian Association of Gastroenterology (CAG) and the Canadian Digestive Health Foundation published guidelines on colon cancer screening in 2004 (2). Since the publication of these guidelines, many advances have been made, thereby necessitating a review of the 2004 guidelines in the context of new technologies and clinical knowledge.

In addition to advances in colon cancer screening, three influential groups from the United States (US) have published their recommendations (3-5). Given the close geographical and cultural links between Canada and the US, it is appropriate for the 2004 Canadian guidelines to be reviewed in the context of current American recommendations. The present article is limited to recommendations for colon cancer screening for
Le document de principes de la Société canadienne de gastroentérologie sur le dépistage des personnes courant un risque moyen de cancer colorectal : 2010

L'Association canadienne de gastroentérologie et la Fondation canadienne pour la promotion de la santé digestive ont publié des lignes directrices sur le dépistage du cancer du côlon en 2004. Depuis la publication de ces lignes directrices, de nombreux progrès ont été réalisés, ce qui motive la révision des lignes directrices compte tenu des nouvelles technologies et des nouvelles connaissances cliniques. Le groupe des lignes directrices a repéré trois récentes séries de lignes directrices américaines et découvert sept enjeux qui méritaient d'être commentés selon un point de vue canadien. Ces enjeux incluaient, entre autres, le rôle du dépistage d'après le programme, la sigmoïdoscopie flexible, la coloscopie par tomodensitométrie, les lavements barytés et l'amélioration de la qualité. Le groupe a également fourni un contexte justifiant la sélection du test immunochimique fécal pour rechercher le sang occulte dans les selles et expliquant le rôle relatif de la coloscopie comme outil de dépistage primaire. Le groupe a également fait des recommandations au sujet d'une limite d'âge supérieure pour procéder au dépistage du cancer du côlon, de l'exécution ou non d'une endoscopie supérieure après une coloscopie négative découlant de sang occulte dans les selles et du moment de recommencer le dépistage de cancer du côlon après une coloscopie négative.

average-risk individuals (ie, those with no additional personal or familial risk factors for colon cancer, other than age older than 50 years). Recommendations for those with a family history of colon cancer or a personal history of colonic neoplasia will be addressed in a subsequent article.

\section{METHODS}

The CAG assembled a panel of gastroenterologists including researchers with epidemiology and methodology expertise involved in the delivery of health care related to colon cancer screening and prevention, as well as research and policy making. Representation was available from each major geographical area of Canada - namely, the east, central, prairie and pacific regions.

A PubMed search of the English literature was performed using the search term "colon cancer screening guidelines". The search extended from the date of publication of the Canadian guidelines in February 2004 to July 2010 (2). The three publications retrieved were discussed by the panel in the context of current technologies, clinical knowledge and the Canadian medical environment.

\footnotetext{
${ }^{1}$ Department of Medicine, Dalhousie University, Halifax, Nova Scotia; ${ }^{2}$ St Paul's Hospital, University of British Columbia, Vancouver,

British Columbia; ${ }^{3}$ University of Calgary, Calgary, Alberta; ${ }^{4}$ Centre de santé et de services sociaux Pierre-Boucher, Longueuil and University

of Montreal, Montreal, Quebec; ${ }^{5}$ University of Toronto, Toronto, Ontario; ${ }^{6}$ Royal Alexandra Hospital, University of Alberta, Edmonton,

Alberta; ${ }^{7}$ Departments of Internal Medicine and Community Health Services, University of Manitoba, Winnipeg, Manitoba

Correspondence: Dr Desmond J Leddin, Room 912, Victoria Building, Victoria General Hospital, Halifax, Nova Scotia B3H 2 Y9.

Telephone 902-473-7833, fax 902-473-4406, e-mail dleddin@dal.ca

Received for publication August 24, 2010. Accepted August 30, 2010
} 
TABLE 1

Summary of recommendations of the United States Multi-Society Task Force on Colorectal Cancer (Multi-Society), the American College of Gastroenterology (ACG) and the United States Preventive Services Task Force (USPSTF) regarding age at initiation and tools that may be used for screening and frequency of screening

\begin{tabular}{|c|c|c|c|}
\hline & Multi-Society & ACG & USPSTF \\
\hline Age, years & 50 & 50 (African-American, 45) & 50 \\
\hline Colonoscopy & 10 years & 10 years (preferred) & 10 years \\
\hline Flexible sigmoidoscopy & 5 years & $5-10$ years & $\begin{array}{l}5 \text { years }+ \text { fecal occult blood test } \\
\text { every } 3 \text { years }\end{array}$ \\
\hline Double-contrast barium enema & 5 years & $\begin{array}{l}\text { Replaced by computed tomography } \\
\text { colonography }\end{array}$ & Not addressed \\
\hline Computed tomography colonoscopy & 5 years & 5 years & Insufficient evidence \\
\hline Guaiac fecal occult blood test (high sensitivity) & Annual & Annual & Annual \\
\hline Fecal immunohistochemical tesț & Annual & Annual & Annual \\
\hline Fecal DNA test & Interval uncertain & 3 years & Insufficient evidence \\
\hline
\end{tabular}

\section{SUMMARY OF GUIDELINES RELEASED BY} MAJOR US ORGANIZATIONS SINCE 2004

Three major sets of guidelines from the following organizations were found: the US Preventive Services Task Force (USPSTF) (3), the American College of Gastroenterology (ACG) (4) and the US Multi-Society Task Force on Colorectal Cancer (5). The recommendations from these groups with regard to average-risk screening are summarized in Table 1.

Briefly, all three groups recommend that screening begin at 50 years of age and that fecal occult blood testing (FOBT) be performed annually if that strategy is used. The ACG recommends initiation of screening in African-Americans at 45 years of age.

The US Multi-Society Task Force guidelines (5) recommend that a variety of tools be used, and that the frequency of screening vary with the screening modality. The ACG recommends colonoscopy as the preferred strategy and, also, recommends computed tomography colonography (CTC) every five years over double-contrast barium enema if radiological screening is used.

The USPSTF differs from the other two groups in that it set an upper age limit for screening at 75 years (3), and concluded that there is insufficient evidence to recommend either CTC or fecal DNA testing.

\section{ISSUES AND QUESTIONS ARISING SINCE THE MOST RECENT CAG REVIEW OF COLON CANCER SCREENING (2004)}

The CAG panel identified the following issues as barriers to placing the newer guidelines into a Canadian context:

1. Should the colon cancer screening approach taken be that of opportunistic screening or programmatic populationbased screening?

2. What should be the diagnostic test choice of in programmatic colon cancer screening?

a. Should high-sensitivity guaiac-based FOBT (g-FOBT) or fecal immunochemical testing (FIT) be used in programmatic colon cancer screening?

i. Should FOBT for programmatic colon cancer screening be performed annually or biennially?

b. What is the role of flexible sigmoidoscopy (FS) in programmatic colon cancer screening? c. Should colonoscopy be recommended for population colon cancer screening?

d. Does barium enema have a role in population colon cancer screening?

e. What is the role of CTC in programmatic colon cancer screening?

f. What is the role of fecal DNA testing in programmatic colon cancer screening?

3. What are appropriate diagnostic procedures for opportunistic colon cancer screening?

4. Should there be an upper age limit beyond which colon cancer screening is not recommended?

5. Should upper gastrointestinal endoscopy be performed following a negative colonoscopy for a positive FOBT?

6. When should colon cancer screening be resumed after a negative colonoscopy?

7. What is the role of quality improvement in colon cancer screening?

\section{SHOULD THE COLON CANCER SCREENING APPROACH TAKEN BE THAT OF OPPORTUNISTIC SCREENING OR OF PROGRAMMATIC POPULATION-BASED SCREENING?}

\section{Recommendation:}

- Colon cancer screening in Canada should be delivered through a programmatic regional or provincial program.

The Canadian health care system is based on a number of principles including universal access to health care. Given the premise of universal access, the perspective of the CAG is a societal one. However, another reality of Canadian health care is the reduced number of health care workers and resources per capita compared with the United States. These realities of necessity will influence the choice of a population-based screening tool.

The International Agency for Research on Cancer defines an organized screening program as one that has the following features: an explicit policy with specified age categories, a method and interval for screening, a defined target population, a management team responsible for implementation, a health care team responsible for decisions and care, a quality assurance 
structure and a method for identifying cancer occurrence in the population (6). In contrast, opportunistic screening is performed outside of a programmatic screening program and often delivered through fee-for-service reimbursement of physicians. Compared with opportunistic screening, programmatic screening focuses much greater attention on the quality of the screening process including the follow-up of participants. Thus, a key advantage of organized screening is that it provides greater protection against the harms of screening including overscreening, poor quality and complications of screening, and poor follow-up of those who test positive.

A critical appraisal (7) assessed the evidence for organized programmatic cancer screening by systematically evaluating the published literature from 1966 to 2002 . Although there is a substantial body of literature on programmatic cancer screening, most studies are descriptive and, of those that are evaluative, the focus is on components of the programs rather than the programmatic screening as a whole. For the relatively few studies that evaluated the effectiveness of programmatic versus opportunistic screening, most are from the Scandinavian countries and focus on cervical cancer screening. Madlensky et al (7) concluded that there is limited evidence (level II-2 and II-3) to directly support the effectiveness of programmatic cervical cancer screening, and level III evidence for other cancers. The promise of programmatic cancer screening is that they achieve better accessibility, quality, accountability and outcomes. Thus, the benefits of screening are maximized and harms are reduced. Clearly, further research is needed to determine whether programmatic screening delivers on this promise. For further commentary on opportunistic screening, see section 3 .

\section{WHAT SHOULD BE THE DIAGNOSTIC TEST OF CHOICE IN PROGRAMMATIC COLORECTAL CANCER SCREENING?}

a. Should high-sensitivity g-FOBT or FIT be used in programmatic colon cancer screening?

Recommendation:

- FITs or high sensitivity guaiac-based FOBTs (g-FOBTs) should be used for screening average-risk individuals.

- FIT is preferred.

This recommendation is based on several lines of evidence including high sensitivity, adherence, cost effectiveness and positive predictive value that support the superiority of FITs and high-sensitivity g-FOBTs over older, lower sensitivity g-FOBTs.

The effectiveness of FOBTs, even with lower sensitivity FOBTs, is well supported by large randomized controlled trials (RCTs) (8-10), systematic reviews (11) and economic evaluations $(12,13)$. A meta-analysis of $\mathrm{g}$-FOBTs estimated a $15 \%$ reduction in colorectal cancer mortality from a program of biennial testing (14). Nonetheless, FITs and high-sensitivity g-FOBTs are more sensitive for detecting colorectal cancer than the $\mathrm{g}$-FOBTs used in the published clinical trials (15). In four available cross-sectional studies (16-19) in which all individuals underwent both FIT and colonoscopy, the sensitivity for colorectal cancer ranged from $66 \%$ to $94 \%$.

Adherence to screening is higher for FITs than for $\mathrm{g}$-FOBTs. Two RCTs from the Netherlands $(20,21)$ found an approximately $10 \%$ absolute increase in screening uptake with FITs compared with g-FOBTs. Higher uptake may be the result of fewer dietary restrictions, easier sample collection and/or fewer required samples with FITs. Hemoccult-Sensa (Beckman Coulter USA), which is a three-card test similar to Hemoccult-II (Beckman Coulter Canada), resulted in lower uptake compared with FIT in one study (22).

FIT is more cost effective that g-FOBT. In an economic analysis prepared for the Canadian Agency for Drugs and Technology in Health (12), FIT generated a greater gain in quality-adjusted life years and cost less than g-FOBT.

The higher sensitivity tests often have a lower specificity than older g-FOBTs. This means that there will be more positive tests requiring diagnostic colonoscopy. However, because FIT detects more neoplastic lesions, the positive predictive value (the probability that a significant lesion will be found) is not diminished. The higher sensitivity of FIT combined with the greater test adherence results in a much higher detection rate for advanced adenomas and cancers. For example, in 20,620 individuals randomly assigned to g-FOBT or FIT in the study by van Rossum et al (21), 145 advanced adenomas were ultimately detected in the FIT group compared with only 57 in the g-FOBT group.

It is worth noting that there are several commercially available FITs. They vary in terms of the number of samples required, sampling procedures, processing methods and test characteristics. To achieve the results reported above, a FIT should have sensitivity of higher than $60 \%$ for colorectal cancer and require one or two stool samples. Automated tests have the advantage of being technician independent, supporting central processing of samples and allowing the threshold of a positive test to be changed to match available colonoscopy resources.

\section{i. Should FOBT for programmatic colon cancer screening be performed annually or biennially? \\ Recommendation: \\ - FOBT screening for colon cancer should be performed annually or biennially depending on the resources available in a particular jurisdiction.}

All US guidelines recommend a yearly FOBT, which may be easier to perform as an add-on at the annual physical examination with primary care physicians. Although yearly testing likely has higher efficacy, this has been directly assessed in only one of the four RCTs of FOBTs for colon cancer screening (11). The Minnesota trial (10), which assessed an annual FOBT, used the Hemoccult test and rehydrated the majority of the returned test slides before developing them. Rehydration increases the sensitivity of the FOBT to detect colon cancer, but also markedly increases the number of false-positive tests and is, therefore, not recommended or routinely performed in clinical laboratories (23).

Decision analyses using microsimulation models performed for the Health Canada's committee in 2002 and for USPSTF in 2008, suggested that annual FOBT screening would lead to increased life years gained compared with biennial screening; however, the resources required for annual screening are much greater than for biennial screening $(13,24)$. This was demonstrated in a decision analysis for the USPSTF (13). The number of life years gained increased from 198 to 227 per 1000 individuals who were screened between the ages of 50 and 75 years when annual instead of biennial FIT was performed; this was 
accompanied by an increase in the number of colonoscopies from 2184 to 2949 performed during the lifetime of screening for these individuals. Similar results were found for Hemoccult Sensa using the test characteristics for nonrehydrated Hemoccult Sensa.

\section{b. What is the role of FS in programmatic colon cancer screening? \\ Recommendations:}

- FS for colon cancer screening should be offered to all average-risk individuals.

- The interval between normal sigmoidoscopies should be 10 years or longer.

Several high-quality observational studies published over the past two decades $(25-27)$ suggested that there is a long-term reduction in colon cancer incidence and mortality after FS. There are four ongoing RCTs of FS for colon cancer screening. The three European trials (28-30) are evaluating once per lifetime FS at approximately 60 years of age, and the US trial (31) is evaluating FS once every five years. Two of the European trials have recently published their initial results and the other trails are expected to report their results over the next year or so. The Norwegian Colorectal Cancer Prevention Trial (NORCCAP), which involves a smaller number of study subjects than the United Kingdom (UK) and US trials, found a significant $59 \%$ reduction in colon cancer mortality after a median of six years of follow-up among individuals who underwent FS, and a nonsignificant $27 \%$ reduction in the intentionto-treat analysis (ie, including individuals who were randomly assigned to the FS arm of the trial, but did not undergo the test). More recently, after a median follow-up period of 11.2 years, the larger UK trial (28), reported a 31\% reduction in colon cancer mortality in the intention-to-treat analysis, and a $43 \%$ reduction in colon cancer mortality in per-protocol analyses (adjusted for self-selection bias in the intervention group). The UK trial (28) also reported a $23 \%$ reduction in the incidence of colon cancer in the intention-to-treat analysis and a 33\% colon cancer incidence reduction in the per-protocol analysis.

The UK trial is currently the only RCT that has reported results of long-term follow-up after FS. To date, in this trial, there has been remarkably no attenuation in the beneficial effects of initial FS in the later years of follow-up. Indeed, the differences in cumulative colon cancer incidence and mortality between the intervention and control groups in the study continue to increase by the end of the follow-up period. This result is consistent with earlier observational studies that found no attenuation in effect after a follow-up period of as long as 10 to 16 years after $\mathrm{FS}$.

The magnitude of reduction in colon cancer mortality reported in the two FS trials is greater than that reported with FOBTs in the earlier FOBT trials (11), and it is equivalent to or greater than the breast cancer mortality reduction with mammograms for breast cancer screenings in different age groups (14). Hence, the CAG recommends that provincial screening programs should consider adding FS to the programmatic colon cancer screening. We recognize that this approach will require an expansion of endoscopy capacity, a change in the funding/reimbursement model for FS and consideration of introducing training for nonphysician endoscopists for FS (as is currently being piloted in Ontario). In this regard, a review for the Canadian Agency for Drugs and Technology in Health (32) found no difference in the performance of FS between appropriately trained nonphysician and physician endoscopists. We recommend that Canadian provinces conduct pilot/ feasibility studies for FS through organized regional or provincial programs; only such studies will be able to determine the acceptability of FS in Canada.

\section{c. Should colonoscopy be recommended for population- based colon cancer screening? \\ Recommendation:}

- Colonoscopy is not recommended for population-based colon cancer screening at this time.

There are no previous RCTs that evaluated efficacy and the risk-benefit of colonoscopy in the reduction of colon cancer incidence and mortality. Recently initiated trials are, however, underway, but will not report in the near future.

There is considerable indirect evidence that colonoscopy is effective in reducing the incidence and mortality from colon cancer (33-38), and there is evidence for a reduction in cancer incidence and mortality when FS is used for screening $(28,39)$. Therefore, it seems reasonable to assume that colonoscopy will be shown in RCTs to be at least as, if not more, effective as FS because colonoscopy does examine more segments of the colon (40). The results of colonoscopy cohort studies (39) suggest that an FS-only screening strategy would fail to detect $21 \%$ to $65 \%$ of right-sided, advanced neoplasias.

However, recent studies $(2-4,33,41-43)$ have raised questions regarding the magnitude of incremental benefit of colonoscopy over FS when colonoscopy is performed in the usual clinical practice. The potentially limited effectiveness of colonoscopy in usual clinical practice for right-sided colon cancers is likely due to an interplay of the biology of the tumours and technical performance of colonoscopy. The nonpolypoid and serrated lesions, which are more common in the right colon and are endoscopically subtle, may be less often detected by certain endoscopists $(6,44)$. Many right-sided lesions will not be detected by endoscopists who have low cecal intubation rates and by those who do not carefully and thoroughly evaluate the colon.

In addition, colonoscopy requires greater skill than sigmoidoscopy, a more intensive bowel cleansing regimen and is more costly. It also requires more human resources, sedation and may incur a greater risk of complications including bleeding, perforation and death. Given the increased risk and costs of colonoscopy without currently demonstrated benefit over FS in usual clinical practice, colonoscopy is not recommended as a population-based strategy at this time.

\section{d. Does barium enema have a role in population colon cancer screening? \\ Recommendation:}

- Air-contrast barium enema should no longer have a role in population screening for colon cancer.

The role of air-contrast barium enemas appears to be diminishing. Many centres in Canada are slowly 'phasing out' their barium studies and have replaced them with computed tomographybased imaging (40). With each passing year, trainees are less likely to be well trained in performing barium studies. Despite this, it is conceivable that, in some sites, barium studies may be 
considered a proposed study for colon screening, particularly in the scenario of a failed colonoscopy. The limitations of doublecontrast barium enemas need to be recognized in this setting. Compared with CTC (even excluding polyps smaller than $6 \mathrm{~mm}$ in size), there are several studies including meta-analyses (45-47) that have demonstrated the inferiority of barium studies compared with CTC. When compared with colonoscopy, aircontrast barium enema has been demonstrated in prospective, tandem studies to be inferior. For lesions $10 \mathrm{~mm}$ in size or greater, the sensitivity of air-contrast barium enema was less than $50 \%$ compared with optical colonoscopy $(48,49)$. In a similar fashion, a meta-analysis (50) comparing air-contrast barium enema with other modalities of radiological imaging and optical colonoscopy confirmed that air-contrast barium enema is inferior to both colonoscopy and CTC. Patient preference has also favoured other modalities over air-contrast barium enema (51), and the radiation dose may actually favour CTC (52). Overall, it appears that the lack of sensitivity of aircontrast barium enema limits its usefulness, particularly in an era in which colonoscopy is widely available and CTC availability is expanding. For these reasons, we believe that aircontrast barium enema has no role in screening average-risk patients for colon cancer.

e. What is the role of CTC in programmatic colon cancer screening?

Recommendation:

- CTC is not recommended for population screening.

- We endorse the use of CTC for other selected cases.

The advent of CTC has changed some of the management strategies for colon cancer screening. For primary screening in average-risk patients, a major issue is the sensitivity of CTC for polyps smaller than $6 \mathrm{~mm}$. These polyps are not detected reliably with this imaging modality. For this reason, the American College of Radiology (ACR) does not recommend reporting polyps that are $5 \mathrm{~mm}$ in size or smaller. In the case of a single polyp $6 \mathrm{~mm}$ to $9 \mathrm{~mm}$ in size, the ACR suggests a follow-up CTC in three years (53). For patients with three or more polyps $6 \mathrm{~mm}$ to $9 \mathrm{~mm}$ in size, or those with presumed advanced adenomas, an optical colonoscopy is recommended. If CTC is normal in an average-risk patient, repeat CTC in five years is recommended. These recommendations are based on data suggesting a sensitivity of $85 \%$ to $93 \%$, and a specificity of $97 \%$ for the detection of large polyps (10 $\mathrm{mm}$ or larger) and a sensitivity of $70 \%$ to $86 \%$, and specificity of $86 \%$ to $94 \%$ for polyps $6 \mathrm{~mm}$ to $9 \mathrm{~mm}$ in size $(54,55)$.

There are several reasons why CTC is not presently appropriate for generalized screening in Canada. First, patients with three or more adenomas (regardless of size) are considered to be high risk; this finding has been demonstrated to be a risk factor for future adenomatous polyps (56). Because polyps smaller than $6 \mathrm{~mm}$ are not reported with CTC, the group of patients with three or more diminutive polyps would be missed entirely by CTC. A recent database analysis comparing CTC recommendations from the ACR (57) demonstrated that 33\% of all patients would be classified as normal when they had high-risk lesions using the ACR recommendations.

Second, the suggested intervals for follow-up in patients with normal CTC results are shorter than those for optical colonoscopy (five years versus 10 years, respectively). In Canada, similar cost requirements apply to colonoscopy and CTC (and both require full colonic preparation). For patients with normal studies, a repeat study every five years is twice as many procedures as would be performed in the colonoscopy setting. This increases overall costs for screening procedures in those with normal studies as well as in those in whom polyps are found. This does not take into account patients with polyps requiring colonoscopy following their CTC. Decision analyses (58) have confirmed that overall costs are increased with the use of CTC when compared with other methods of colon cancer screening.

Third, the issue of radiation risk is frequently raised with CTC. While there are different methods to calculate radiation dose, most commonly, a CTC examination in an individual 50 years of age is believed to deliver an organ dose to the colon of $7 \mathrm{mSv}$ to $13 \mathrm{mSv}$ ( $65 \mathrm{mAs}$ ), which is estimated to add an additional $0.044 \%$ to the lifetime risk of colon cancer (59). For these reasons, the USPSTF believes that the evidence was insufficient to assess the benefits and harms of CTC as a screening modality for colorectal cancer (3). The ACG guidelines (60) also weighed in favour of colonoscopy over CTC.

The use of CTC for selected indications is endorsed by the CAG. Completion rates for screening colonoscopy should exceed 95\%; however, there will always be procedures that are difficult to complete. There are several options for these patients, although in the past, double-contrast barium enema was used by most institutions. With the gradual implementation of CTC and the presumed decrease in both training and performance of double-contrast barium enema, it seems reasonable to consider using a CTC to 'clear' the colon of areas not endoscopically visualized. It should be recognized, however, that other options clearly include referral to expert centres where completion rates may be maximized by personal and equipment differences. The advent of balloon technology has created an environment in which many expert investigators can complete the vast majority of previously failed studies endoscopically, thereby providing a 10-year interval if viewed to be normal in this patient population. Other options under development include colon capsule endoscopy. However, contemporary comparative studies are limited.

\section{$\mathrm{f}$. What is the role of fecal DNA testing in programmatic colon cancer screening? \\ Recommendation: \\ - Fecal DNA testing is currently not recommended for programmatic colon cancer screening.}

Fecal DNA testing for the detection of adenomas and colon cancer is based on the observation that DNA mutations occur as colonic tissue changes from normal to neoplastic. Progression through the normal tissue, to adenoma, to carcinoma sequence is characterized by multiple mutations, and current iterations of fecal DNA tests search for a panel of DNA changes rather than a single mutation. Successive generations of the test use different combinations of mutations in an attempt to optimize performance. The theoretical advantages of fecal DNA testing include its noninvasive nature, its ability to access the test regardless of geographical location, potentially greater sensitivity in the detection of proximal lesions and the ability to eventually screen the entire gastrointestinal tract (61). Two well-known studies have been performed comparing 
fecal DNA tests to standard FOBT (62). Outcomes included polyp detection, cancer detection and screen-relevant neoplasia (defined as early-stage cancer, high-grade dysplasia or adenomas larger than $1 \mathrm{~cm}$ ). Test performance was similar in sensitivity and specificity to that of FOBT. This has led to the endorsement of fecal DNA testing as a screening tool by both the Multi-Society Task Force on Colorectal Cancer and the ACG. Nonetheless, uncertainty remains over timing intervals for screening and how to proceed in patients with a positive fecal DNA test and negative colonoscopy. Moreover, cost is greater compared with FOBT, and evidence of the performance and efficacy of fecal DNA testing in population-based trials is lacking. Pending the answers to these questions and the results of such a trial, combined with the fact that no fecal DNA test has been approved by Health Canada nor are these tests commercially available in Canada, we do not recommend that fecal DNA testing be used as a first-line screening tool.

\section{WHAT ARE APPROPRIATE OPTIONS FOR OPPORTUNISTIC COLON CANCER SCREENING?} Recommendations:

- FOBT (preferably FIT), FS and colonoscopy are all appropriate options for opportunistic colon cancer screening.

- CTC is not recommended for opportunistic screening.

- Opportunistic screening should be performed in accordance with the quality standards applicable to population screening programs.

While programmatic colon cancer screening is being developed in most provinces, and the CAG supports programmatic screening approaches, we recognize that much of the current colon cancer screening in Canada occurs outside of programmatic screening programs. Opportunistic screening using a variety of screening tools may be appropriate due to patient preferences and if resources permit. With regard to individual screening, therefore, individual patients and individual physicians may make different choices as to the screening tool they use. Local health care environments may allow for the deployment of screening methods that may not be practicable on a population basis. The evidence that supports the use of FOBT and FS is also applicable to the use of these modalities in opportunistic screening, while the evidence supporting the recommendation for colonoscopy is summarized above.

\section{SHOULD THERE BE AN UPPER AGE LIMIT BEYOND WHICH COLON CANCER SCREENING IS NOT RECOMMENDED?}

Recommendation:

- Programmatic colon cancer screening of adults should cease at 75 years of age.

- A decision to screen individuals 76 to 85 years of age should be made on an individual basis.

- Individuals older than 85 years of age should not be screened.

Colon cancer screening involves a trade-off between risks and benefits. The risks of screening include complications related to bleeding, perforation and cardiorespiratory events. The risk of adverse events related to follow-up colonoscopy increases with increasing age (63). The primary benefits of screening relate to the number of life-years saved. This decreases with increasing age as the number of potential future years decrease and, conversely, the cost per life-year saved by screening increases. The additional benefit to individuals who have been enrolled in a screening program of extending the program beyond 76 years of age is not favourable (15). Thus, the CAG position mirrors that of the USPSTF (3) in that programmatic screening should cease at 75 years of age. However, individual consideration and judgement should be exercised, and there may be circumstances in which routine or opportunistic screening above this age is reasonable. This is particularly applicable to individuals older than 75 years of age who have not been screened previously.

\section{SHOULD UPPER GASTROINTESTINAL ENDOSCOPY BE PERFORMED FOLLOWING A NEGATIVE COLONOSCOPY FOR A POSITIVE FOBT?}

Recommendation:

- Upper endoscopy is not required in every case of negative colonoscopy and positive FOBT. A decision to perform upper endoscopy should be based on clinical judgment and individualized to patient history and findings.

In screening programs, up to $50 \%$ of cases with positive FOBT results will have negative findings at colonoscopy (64). Assuming a colonic lesion was not missed, it is possible that the source of blood loss arises from the upper gastrointestinal tract or small intestine. Upper gastrointestinal sources of blood loss could be the initial presentation of malignancy or other pathology requiring treatment. However, further investigation of FOBT positive/colonoscopy negative cases will subject asymptomatic screen participants to additional invasive investigations and dramatically increase the endoscopy resources needed for a screening program. A recent systematic review on this issue (65) found that gastroscopy had a low diagnostic yield for upper gastrointestinal cancer ( $1 \%$ or less) and that the yield for detecting nonmalignant findings potentially contributing to a positive FOBT was $11 \%$ to $21 \%$. The authors suggested that the current body of evidence was insufficient to recommend for or against routine esophagogastroduodenoscopy as a means of detecting gastric or esophageal cancers for patients who are FOBT positive/colonoscopy negative participating in a population-based colorectal cancer screening program. They also believed that the decision to perform esophagogastroduodenoscopy should be individualized and based on clinical judgment of other indications for esophagogastroduodenoscopy.

One of the stated advantages of FIT is that it may reduce the number of positive stool tests resulting from upper gastroinestinal blood loss because the globin portion of the hemoglobin molecule is degraded during transit through the gastrointestinal tract. Using this test may reduce the number of positive stool tests secondary to upper gastrointestinal lesions.

\section{WHEN SHOULD COLON CANCER SCREENING BE RESUMED AFTER A NEGATIVE COLONOSCOPY?}

Recommendation:

- Following a negative colonscopy investigation for a positive FOBT, individuals should return to an 
average-risk pathway with screening resumed in 10 years or longer.

It is assumed that a negative colonoscopy provides a protective effect against the downstream development of colorectal cancer for up to 10 years. This assumption is based on indirect evidence arising from what is known about the natural history of the colonic adenomatous polyp and from cohort observational studies in patients undergoing colonoscopic polypectomy $(33,36,38,66)$. Additional observational studies with scheduled repeat colonoscopy have also demonstrated a low five-year risk of developing advanced neoplasia after a baseline high-quality colonoscopy $(67,68)$. As well, a recent FS screening trial (28) demonstrated a long-term protective effect extending beyond 10 years. Given this evidence, the CAG recommends that average-risk screen participants who have negative findings at colonoscopy do not require colon cancer screening for the subsequent 10 years unless new bowel symptoms develop.

\section{WHAT IS THE ROLE OF QUALITY IMPROVEMENT IN COLON CANCER SCREENING?}

Recommendation:

- The CAG recommends that all programmatic colon cancer screening and opportunistic screening activity operate within established quality assurance standards.

Regardless of whether screening is performed within programs or is opportunistic, it is extremely important to document high-quality performance of any colon cancer screening activity. Several recent studies $(43,63,69,70)$ have suggested that there is a significant variation in colonoscopy outcomes that is dependent on the endoscopist performing the index colonoscopy. The individual endoscopist can be a more important predictor of detecting adenomas than even the demographics of the individual undergoing the colonoscopy (71). Therefore, the CAG believes that it is extremely important for all endoscopists to record and monitor their outcomes and participate in quality assurance programs, regardless of whether colon cancer screening is performed through organized programs or opportunistically. The emphasis on quality must be higher for colon cancer screening because screening is performed on asymptomatic individuals. The emphasis on quality also must be higher for colonoscopy performance given the wide variation in colonoscopist-dependent colonoscopy outcomes.

To reduce mortality from colon cancer in the population, a screening program must be able to provide screening tests of adequate sensitivity to detect early colon cancers and, preferably, advanced adenomas. The program must have effective strategies to ensure that the target population accepts and uses the screening services offered. Screening programs must also strive to minimize any serious adverse effects, including complications from colonoscopy. As part of their quality assurance programs, screening programs should identify and measure key quality indicators on a regular basis. Key quality indicators for colonoscopy have been defined by a joint American Society of Gastrointestinal Endoscopy/American College of Gastroenterology Task Force on Quality in Endoscopy (72). At minimum, endoscopists should measure their cecal intubation rate, adenoma detection rate and serious complication rate (perforation, postpolypectomy hemorrhage), and compare their performance with published benchmarks. The CAG recommends that all endoscopists providing colonoscopy as a primary colon cancer screening test or as a diagnostic follow-up test after an alternative screening test such as an FOBT, should participate in an organized continuous quality improvement program. In the absence of such a program, endoscopists should perform self-assessment audits of their colonoscopy performance by measuring key quality indicators. The ability to monitor all aspects of quality is a major advantage of programmatic as opposed to opportunistic screening. The CAG is actively involved in an endoscopy quality assurance program. The principles and methodology of this program are applicable to the colon cancer screening programs that are being developed by the provinces. The delivery of a high-quality screening program has a broader focus than endoscopy, and involves many other aspects of the health care system including pathology, radiology, surgery and oncology services. The CAG and Canadian gastroenterologists should play an active part in promoting quality-based principles as screening programs are developed in their areas.

\section{CONCLUSION}

The weight of medical evidence is clearly in support of colon cancer screening. The CAG believes that this preventive health strategy is now part of the standard of care in Canada for individuals 50 to 75 years of age (see Appendix for a summary of the CAG recommendations). Ideally, colorectal cancer screening should be performed as part of an organized population-based program. These initiatives are beginning to appear in some regions of the country; however, much work remains to be completed to extend the benefits of screening to all Canadians.

DISCLOSURE: The authors have no financial disclosures or potential conflicts of interest to declare.

FINANCIAL SUPPORT: This review was endorsed and organized by the CAG. Panel Consensus members did not receive compensation (eg, honoraria or travel expenses) from the CAG or industry for their participation.

\section{APPENDIX: SUMMARY OF RECOMMENDATIONS}

1. Should the colon cancer screening approach
taken be that of opportunistic screening or
programmatic population-based screening?
Recommendation: Colon cancer screening in Canada
should be delivered through a programmatic
regional or provincial program.
2. What should be the choice of diagnostic in
programmatic colon cancer screening?
a. Should high sensitivity guaiac or fecal
immunochemical testing be utilized in
programmatic colon cancer screening?
Recommendation: Fecal immunochemical or high
sensitivity guiaic-based fecal occult blood testing
(FOBT) should be used for screening average
risk individuals. Fecal immunochemical testing is
preferred.




\section{i. Should FOBT for programmatic colon cancer} screening be performed annually or biennially?

Recommendation: FOBT screening for colon cancer should be performed at least every two years. FOBT is an acceptable alternative option depending on the resources available in a particular jurisdiction

b. What is the role of flexible sigmoidoscopy in programmatic colon cancer screening?

Recommendation: Flexible sigmoidoscopy for colon cancer screening should be offered to all averagerisk individuals. The interval between normal sigmoidoscopies should be 10 years or longer.

c. Should colonoscopy be recommended for population colon cancer screening?

Recommendation: Colonoscopy is not recommended for population screening at this time.

d. Does barium enema have a role in population colon cancer screening?

Recommendation: Air-contrast barium enema should no longer have a role in population screening for colon cancer.

e. What is the role of computed tomography colonography (CTC) in programmatic colon cancer screening?

Recommendation: CTC is not recommended for population screening. We endorse the use of CTC for other selected cases.

f. What is the role of fecal DNA in programmatic colon cancer screening?

Recommendation: Fecal DNA testing is currently not recommended for programmatic screening.

3. What are appropriate diagnostic procedures for opportunistic colon cancer screening?

Recommendation: FOBT (preferably fecal immunochemical testing), flexible sigmoidoscopy, and colonoscopy are appropriate for opportunistic colon cancer screening. CTC is not recommended for opportunistic colon cancer screening. Opportunistic screening should be performed in accordance with the quality standards applicable to population screening programs.

4. Should there be an upper age limit beyond which colon cancer screening is not recommended?

Recommendation: Programmatic screening of adults should cease at 75 years of age. A decision to screen individuals 76 to 85 years of age should be made on an individual basis. Individuals older than 85 years of age should not be screened.

5. Should upper gastrointestinal endoscopy be performed following a negative colonoscopy for a positive FOBT?

Recommendation: Upper endoscopy is not required in every case when a negative colonoscopy is the result of a positive FOBT. A decision to perform upper endoscopy should be based on clinical judgment and individualized to patient history and findings.

6. When should colon cancer screening be resumed after a negative colonoscopy?

Recommendation: Following a negative colonoscopy for positive FOBT, individuals should return to an average-risk pathway, with screening resumed in 10 years.

7. What is the role of quality improvement in colon cancer screening?

Recommendation: The CAG recommends that all programmatic colorectal cancer screening programs and opportunistic screening activity operate within established quality assurance standards.

\section{REFERENCES}

1. Canadian Cancer Society and NCIO Canada, Canadian cancer statistics 2008. 2008, Canadian Cancer Society: Toronto.

<http://www.cancer.ca/ /media/CCS/Canada\%20wide/Files\%20List/ English\%20files\%20heading/pdf\%20not\%20in\%20publications\%20 section/Canadian\%20Cancer\%20Society\%20Statistics\%20PDF\%20 2008_614137951.ashx> (Accessed on October 28, 2010).

2. Leddin D, Hunt R, Champion M, et al. Canadian Association of Gastroenterology and the Canadian Digestive Health Foundation: Guidelines on colon cancer screening. Can J Gastroenterol 2004;18:93-9.

3. U.S. Preventive Services Task Force. Screening for colorectal cancer: U.S. Preventive Services Task Force recommendation statement. Ann Intern Med 2008;149:627-37.

4. Dominic OG, McGarrity T, Dignan M, Lengerich EJ. American College of Gastroenterology Guidelines for colorectal cancer screening 2008. Am J Gastroenterol 2009;104:2626-7;

5. Levin B, Lieberman DA, McFarland B, et al. Screening and surveillance for the early detection of colorectal cancer and adenomatous polyps, 2008: A joint guideline from the American Cancer Society, the US Multi-Society Task Force on Colorectal Cancer, and the American College of Radiology. Gastroenterology 2008;134:1570-95.

6. International Agency for Research on Cancer and World Health Organization. Cervix cancer screening, 1st edn, vol 10.

Lyon: IARC Press, 2005.
7. Madlensky L, Goel V, Polzer J, Ashbury FD. Assessing the evidence for organised cancer screening programmes. Eur J Cancer 2003;39:1648-53.

8. Kewenter J, Brevinge H, Engaras B, Haglind E, Ahren C. Results of screening, rescreening, and follow-up in a prospective randomized study for detection of colorectal cancer by fecal occult blood testing. Results for 68,308 subjects. Scand J Gastroenterol 1994;29:468-73.

9. Kronborg O, Fenger C, Olsen J, Jorgensen OD, Sondergaard O. Randomised study of screening for colorectal cancer with faecal-occult-blood test. Lancet 1996;348:1467-71.

10. Mandel JS, Bond JH, Church TR, et al. Reducing mortality from colorectal cancer by screening for fecal occult blood. Minnesota Colon Cancer Control Study. N Engl J Med 1993;328:1365-71.

11. Hewitson P, Glasziou P, Watson E, Towler B, Irwig L.

Cochrane systematic review of colorectal cancer screening using the fecal occult blood test (hemoccult): An update. Am J Gastroenterol 2008;103:1541-9.

12. Heitman S, Au F, Hilsden R, Manns B. Fecal immunochemical testing in colorectal cancer screening of average risk individuals: Economic evaluation. Health OCAfDaTi, 2009. < http://www.acmts. ca/media/pdf/M0012_FIT_Economic_Evaluation_L3_e.pdf $>$ (Accessed on October 8, 2010).

13. Zauber AG, Lansdorp-Vogelaar I, Knudsen AB, Wilschut J, van Ballegooijen M, Kuntz KM. Evaluating test strategies for colorectal cancer screening: A decision analysis for the U.S. Preventive Services Task Force. Ann Intern Med 2008;149:659-69. 
14. Nelson HD, Tyne K, Naik A, Bougatsos C, Chan BK, Humphrey L. Screening for breast cancer: An update for the U.S. Preventive Services Task Force. Ann Intern Med 2009;151:727-37, W237-42.

15. Whitlock EP, Lin JS, Liles E, Beil TL, Fu R. Screening for colorectal cancer: A targeted, updated systematic review for the U.S. Preventive Services Task Force. Ann Intern Med 2008;149:638-58.

16. Cheng TI, Wong JM, Hong CF, et al. Colorectal cancer screening in asymptomaic adults: Comparison of colonoscopy, sigmoidoscopy and fecal occult blood tests. J Formos Med Assoc 2002;101:685-90.

17. Levi Z, Rozen P, Hazazi R, et al. A quantitative immunochemical fecal occult blood test for colorectal neoplasia. Ann Intern Med 2007;146:244-55.

18. Morikawa T, Kato J, Yamaji Y, Wada R, Mitsushima T, Shiratori Y. A comparison of the immunochemical fecal occult blood test and total colonoscopy in the asymptomatic population. Gastroenterology 2005;129:422-8.

19. Nakama H, Zhang B, Zhang X. Evaluation of the optimum cut-off point in immunochemical occult blood testing in screening for colorectal cancer. Eur J Cancer 2001;37:398-401.

20. Hol L, Wilschut JA, van Ballegooijen M, et al. Screening for colorectal cancer: Random comparison of guaiac and immunochemical faecal occult blood testing at different cut-off levels. Br J Cancer 2009;100:1103-10.

21. van Rossum LG, van Rijn AF, Laheij RJ, et al. Random comparison of guaiac and immunochemical fecal occult blood tests for colorectal cancer in a screening population. Gastroenterology 2008;135:82-90.

22. Cole SR, Young GP, Esterman A, Cadd B, Morcom J. A randomised trial of the impact of new faecal haemoglobin test technologies on population participation in screening for colorectal cancer. J Med Screen 2003;10:117-22.

23. Rabeneck L, Zwaal C, Goodman JH, Mai V, Zamkanei M. Cancer Care Ontario guaiac fecal occult blood test (FOBT) laboratory standards: Evidentiary base and recommendations. Clin Biochem 2008;41:1289-305.

24. Coombs A, Jones-McLean E, Le-Petit C. Technical report for the National Committee on Colorectal Cancer Screening. $<$ http://www.phac-aspc.gc.ca/publicat/ncccs-cndcc/techrep-eng. php> (Accessed on November 10, 2010).

25. Newcomb PA, Norfleet RG, Storer BE, Surawicz TS, Marcus PM. Screening sigmoidoscopy and colorectal cancer mortality. J Natl Cancer Inst 1992;84:1572-5.

26. Newcomb PA, Storer BE, Morimoto LM, Templeton A, Potter JD. Long-term efficacy of sigmoidoscopy in the reduction of colorectal cancer incidence. J Natl Cancer Inst 2003;95:622-5.

27. Selby JV, Friedman GD, Quesenberry CP Jr, Weiss NS. A case-control study of screening sigmoidoscopy and mortality from colorectal cancer. N Engl J Med 1992;326:653-7.

28. Atkin WS, Edwards R, Kralj-Hans I, et al. Once-only flexible sigmoidoscopy screening in prevention of colorectal cancer: A multicentre randomised controlled trial. Lancet 2010;375:1624-33.

29. Hoff G, Grotmol T, Skovlund E, Bretthauer M. Risk of colorectal cancer seven years after flexible sigmoidoscopy screening: Randomised controlled trial. BMJ 2009;338:b1846.

30. Segnan N, Senore C, Andreoni B, et al. Baseline findings of the Italian multicenter randomized controlled trial of "once-only sigmoidoscopy" - SCORE. J Natl Cancer Inst 2002;94:1763-72.

31. Weissfeld JL, Schoen RE, Pinsky PF, et al. Flexible sigmoidoscopy in the PLCO cancer screening trial: Results from the baseline screening examination of a randomized trial. J Natl Cancer Inst 2005;97:989-97.

32. Ho C, Jacobs P, Sandha G, Noorani H, Skidmore B. Non-physicians performing screening flexible sigmoidoscopy: Clinical efficacy and cost-effectiveness (Technology report no 60). Assessment OCCOfHT, 2006. <http://www.cadth.ca/media/pdf/277_ endoscopist_model_tr_e.pdf $>$ (Accessed on October 8, 2010).

33. Baxter NN, Goldwasser MA, Paszat LF, Saskin R, Urbach DR, Rabeneck L. Association of colonoscopy and death from colorectal cancer. Ann Intern Med 2009;150:1-8.

34. Mandel JS, Church TR, Bond JH, et al. The effect of fecal occult-blood screening on the incidence of colorectal cancer. N Engl J Med 2000;343:1603-7.

35. Muller AD, Sonnenberg A. Protection by endoscopy against death from colorectal cancer. A case-control study among veterans. Arch Intern Med 1995;155:1741-8.
36. Singh H, Turner D, Xue L, Targownik LE, Bernstein CN. Risk of developing colorectal cancer following a negative colonoscopy examination: Evidence for a 10-year interval between colonoscopies. JAMA 2006;295:2366-73.

37. Thiis-Evensen E, Hoff GS, Sauar J, Langmark F, Majak BM, Vatn MH. Population-based surveillance by colonoscopy: Effect on the incidence of colorectal cancer. Telemark Polyp Study I. Scand J Gastroenterol 1999;34:414-20.

38. Winawer SJ, Zauber AG, Ho MN, et al. Prevention of colorectal cancer by colonoscopic polypectomy. The National Polyp Study Workgroup. N Engl J Med 1993;329:1977-81.

39. Canadian Partnership Against Cancer. Flexible sigmoidoscopy watching brief 2 nd iteration of expert panel report, 2010. $<$ http://www.partnershipagainstcancer.ca/sites/default/files/FS_ Watching_Brief_2nd_Iteration_Final_ENG.pdf> (Accessed on October 8, 2010).

40. Stevenson G. Colon imaging in radiology departments in 2008: Goodbye to the routine double contrast barium enema. Can Assoc Radiol J 2008;59:174-82.

41. Brenner H, Hoffmeister M, Arndt V, Stegmaier C, Altenhofen L, Haug U. Protection from right- and left-sided colorectal neoplasms after colonoscopy: Population-based study. J Natl Cancer Inst 2010;102:89-95.

42. Lakoff J, Paszat LF, Saskin R, Rabeneck L. Risk of developing proximal versus distal colorectal cancer after a negative colonoscopy: A population-based study. Clin Gastroenterol Hepatol 2008;6:1117-21.

43. Singh H, Nugent Z, Mahmud SM, Demers AA, Bernstein CN. Predictors of colorectal cancer after negative colonoscopy: A population-based study. Am J Gastroenterol 2010;105:663-73.

44. Rex DK. Preventing colorectal cancer and cancer mortality with colonoscopy: What we know and what we don't know. Endoscopy 2010;42:320-3.

45. Johnson CD, MacCarty RL, Welch TJ, et al. Comparison of the relative sensitivity of CT colonography and double-contrast barium enema for screen detection of colorectal polyps. Clin Gastroenterol Hepatol 2004;2:314-21.

46. Ramos C, De Jesus-Caraballo J, Toro DH, et al. Is barium enema an adequate diagnostic test for the evaluation of patients with positive fecal occult blood? Bol Asoc Med P R 2009;101:23-8.

47. Sosna J, Sella T, Sy O, et al. Critical analysis of the performance of double-contrast barium enema for detecting colorectal polyps $>$ or $=6 \mathrm{~mm}$ in the era of CT colonography. AJR Am J Roentgenol 2008;190:374-85.

48. Rockey DC, Koch J, Yee J, McQuaid KR, Halvorsen RA. Prospective comparison of air-contrast barium enema and colonoscopy in patients with fecal occult blood: A pilot study. Gastrointest Endosc 2004;60:953-8.

49. Rockey DC, Paulson E, Niedzwiecki D, et al. Analysis of air contrast barium enema, computed tomographic colonography, and colonoscopy: Prospective comparison. Lancet 2005;365:305-11.

50. Rosman AS, Korsten MA. Meta-analysis comparing CT colonography, air contrast barium enema, and colonoscopy. Am J Med 2007;120:203-10,e4.

51. Bosworth HB, Rockey DC, Paulson EK, et al. Prospective comparison of patient experience with colon imaging tests. Am J Med 2006;119:791-9.

52. Neri E, Faggioni L, Cerri F, et al. CT colonography versus double-contrast barium enema for screening of colorectal cancer: Comparison of radiation burden. Abdom Imaging 2009;35:596-601.

53. Zalis ME, Barish MA, Choi JR, et al. CT colonography reporting and data system: A consensus proposal. Radiology 2005;236:3-9.

54. Halligan S, Altman DG, Taylor SA, et al. CT colonography in the detection of colorectal polyps and cancer: Systematic review, meta-analysis, and proposed minimum data set for study level reporting. Radiology 2005;237:893-904.

55. Mulhall BP, Veerappan GR, Jackson JL. Meta-analysis: Computed tomographic colonography. Ann Intern Med 2005;142:635-50.

56. Winawer SJ, Zauber AG, Fletcher RH, et al. Guidelines for colonoscopy surveillance after polypectomy: A consensus update by the US Multi-Society Task Force on Colorectal Cancer and the American Cancer Society. Gastroenterology 2006;130:1872-85.

57. Rex DK, Overhiser AJ, Chen SC, Cummings OW, Ulbright TM. Estimation of impact of American College of Radiology recommendations on CT colonography reporting for resection of high-risk adenoma findings. Am J Gastroenterol 2009;104:149-53. 
58. Telford JJ, Levy AR, Sambrook JC, Zou D, Enns RA. The cost-effectiveness of screening for colorectal cancer. CMAJ 2007;182:1307-13.

59. Brenner DJ, Georgsson MA. Mass screening with CT colonography: Should the radiation exposure be of concern? Gastroenterology 2005;129:328-37.

60. Rex DK, Johnson DA, Anderson JC, Schoenfeld PS, Burke CA, Inadomi JM. American College of Gastroenterology guidelines for colorectal cancer screening 2008. Am J Gastroenterol 2009;104:739-50.

61. Ahlquist DA, Sargent DJ, Loprinzi CL, et al. Stool DNA and occult blood testing for screen detection of colorectal neoplasia. Ann Intern Med 2008;149:441-50,W81.

62. Imperiale TF, Ransohoff DF, Itzkowitz SH, Turnbull BA, Ross ME. Fecal DNA versus fecal occult blood for colorectal-cancer screening in an average-risk population. N Engl J Med 2004;351:2704-14.

63. Rabeneck L, Paszat LF, Hilsden RJ, et al. Bleeding and perforation after outpatient colonoscopy and their risk factors in usual clinical practice. Gastroenterology 2008;135:1899-906,906 e1.

64. UK Colorectal Cancer Screening Pilot Group. Results of the first round of a demonstration pilot of screening for colorectal cancer in the United Kingdom. BMJ 2004;329:133.

65. Allard J, Cosby R, Del Giudice ME, Irvine EJ, Morgan D, Tinmouth J. Gastroscopy following a positive fecal occult blood test and negative colonoscopy: Systematic review and guideline. Can J Gastroenterol 2010;24:113-20.

66. Citarda F, Tomaselli G, Capocaccia R, Barcherini S, Crespi M. Efficacy in standard clinical practice of colonoscopic polypectomy in reducing colorectal cancer incidence. Gut 2001;48:812-5.

67. Imperiale T, Glowinski E, Lin-Cooper C, Larkin G, Rogge J, Ransohoff D. Five-year risk of colorectal neoplasia after negative screening colonoscopy. N Engl J Med 2008;359:1218-24.

68. Lieberman DA, Weiss DG, Harford WV, et al. Five-year colon surveillance after screening colonoscopy. Gastroenterology 2007;133:1077-85.

69. Rabeneck L, Paszat LF, Saskin R. Endoscopist specialty is associated with incident colorectal cancer after a negative colonoscopy. Clin Gastroenterol Hepatol 2010;8:275-9.

70. Singh H, Penfold RB, De Coster C, Au W, Bernstein CN, Moffatt M. Predictors of serious complications associated with lower gastrointestinal endoscopy in a major city-wide health region. Can J Gastroenterol 2010;24:425-30.

71. Chen SC, Rex DK. Endoscopist can be more powerful than age and male gender in predicting adenoma detection at colonoscopy. Am J Gastroenterol 2007;102:856-61.

72. Rex DK, Petrini JL, Baron TH, et al. Quality indicators for colonoscopy. Gastrointest Endosc 2006;63:S16-28. 


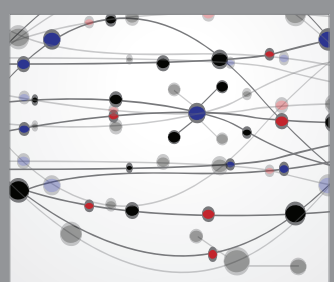

The Scientific World Journal
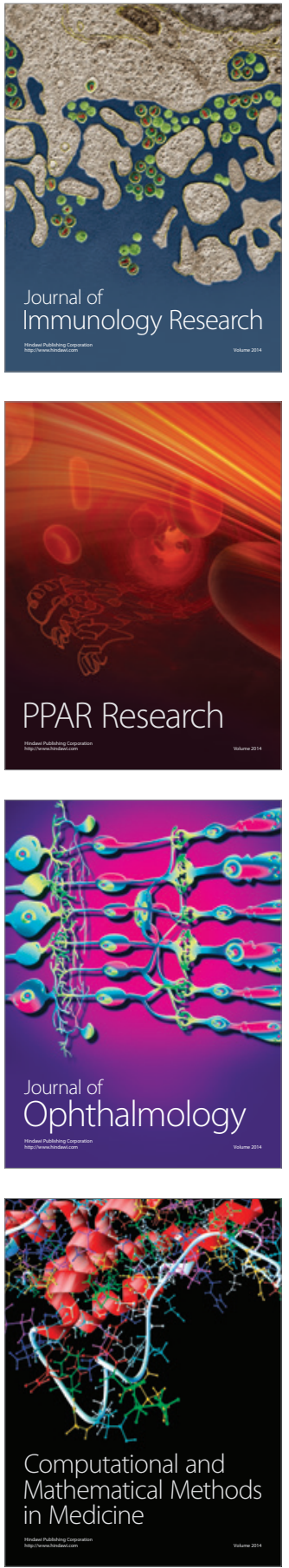

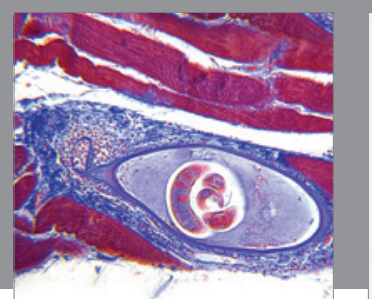

Gastroenterology Research and Practice

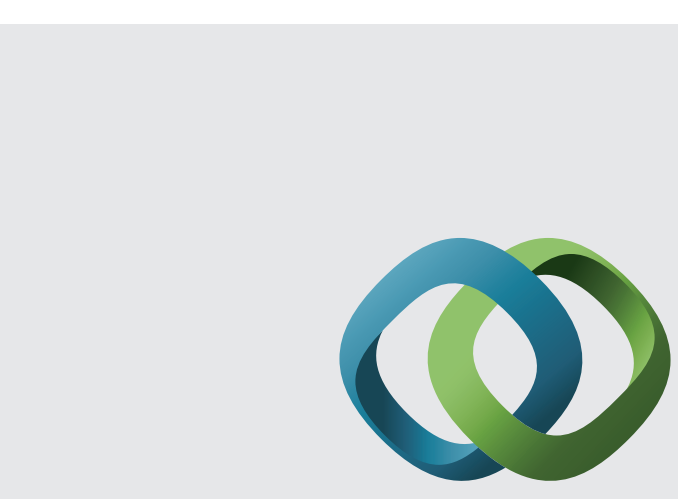

\section{Hindawi}

Submit your manuscripts at

http://www.hindawi.com
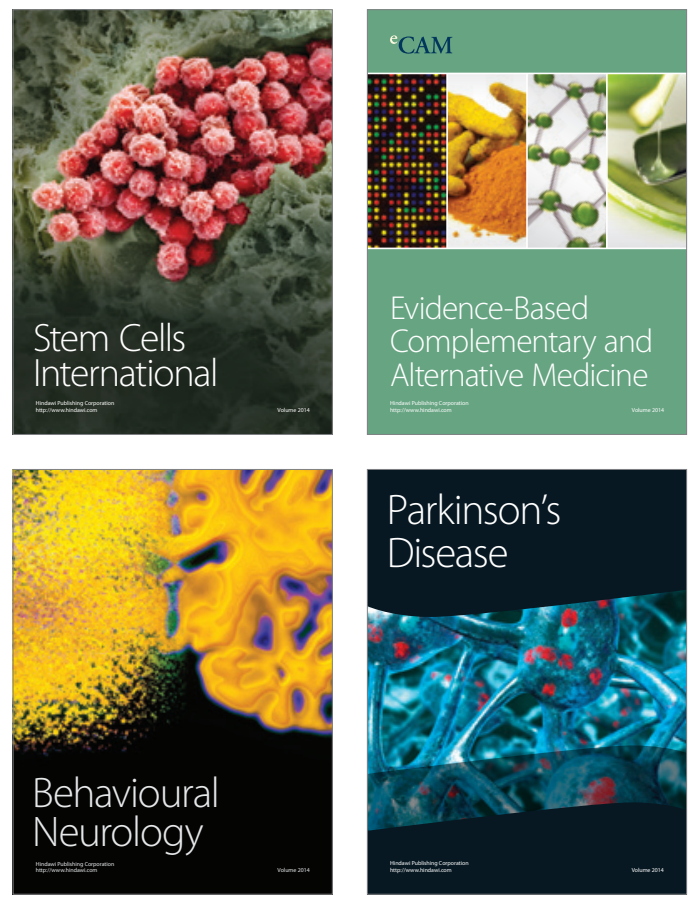
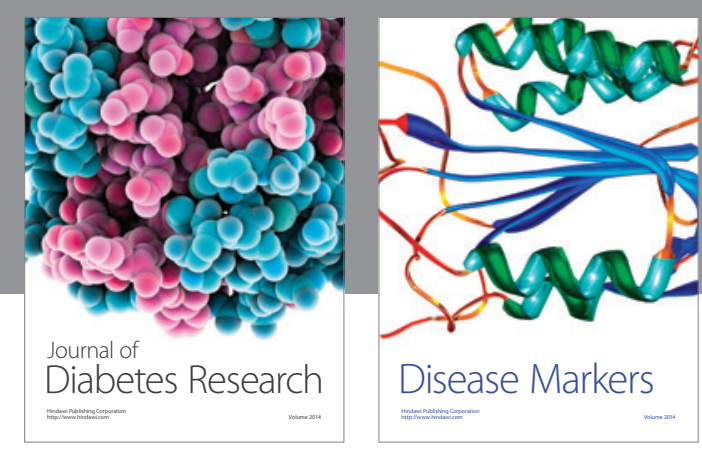

Disease Markers
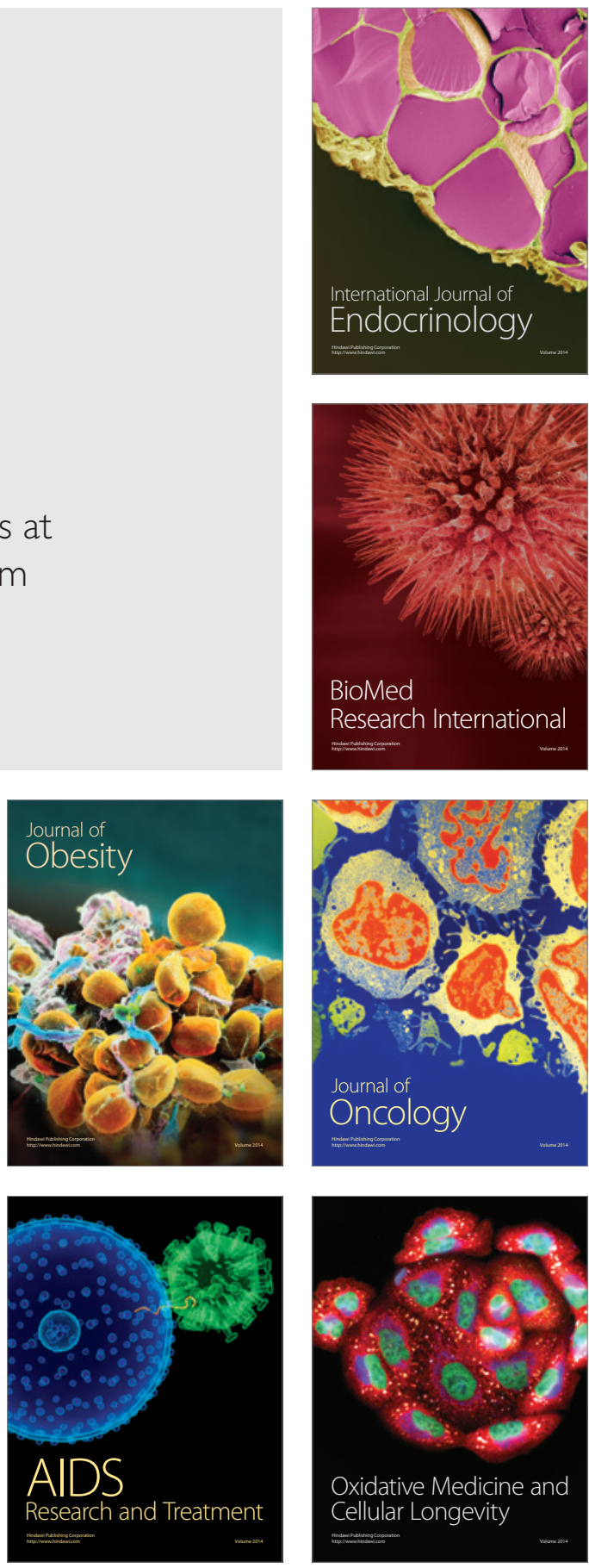